\title{
Antitumor activity of high-dose pulsatile gefitinib in non-small-cell lung cancer with acquired resistance to epidermal growth factor receptor tyrosine kinase inhibitors
}

\author{
YITAO WAN $^{1}$, YUAN YUAN ${ }^{2}$, YUEYIN PAN $^{3}$ and YING ZHANG ${ }^{1}$ \\ ${ }^{1}$ Department of Geriatrics; ${ }^{2}$ Central Laboratory of Binhu Hospital, The Third Affiliated Hospital of Anhui Medical University, \\ Hefei, Anhui 230601; ${ }^{3}$ Department of Oncology, The First Affiliated Hospital of Anhui Medical University, \\ Hefei, Anhui 230022, P.R. China
}

Received August 18, 2015; Accepted January 6, 2017

DOI: 10.3892/etm.2017.4356

\begin{abstract}
Epidermal growth factor receptor tyrosine kinase inhibitors (EGFR-TKIs) have demonstrated efficacy in the treatment of advanced non-small cell lung cancer (NSCLC). However, their clinical efficacy is limited by acquired resistance. Drug resistance may be mediated by EGFR transduction, and a number of clinical trials have demonstrated that high-dose pulsatile TKIs may be effective at treating patients with acquired resistance, though their underlying mechanisms of action remain unknown. The aim of the present study was to investigate the antitumor activity of high-dose pulsatile gefitinib in NSCLC model cell lines, namely the EGFR-TKI-sensitive cell line PC9, as a control group, and the EGFR-TKI-resistant cell lines H1975 and H1650. The cell lines were administered with different doses of gefitinib and cell viability was measured using an MTT assay. Cell apoptosis and cycling were also determined by flow cytometry and the expression of phospho (p)-EGFR, EGFR, p-AKT and AKT were measured by western blot analysis. It was observed that the apoptotic rate of H1975 cells treated with high-dose pulsatile gefitinib significantly increased, while levels of p-EGFR and p-AKT were decreased. However, there was no significant difference in the apoptotic rate or level of p-AKT in gefitinib-treated H1650 cells, while p-EGFR levels decreased. By contrast, the EGFR-TKI-sensitive cell line PC9 exhibited sensitivity to gefitinib. It was demonstrated that the apoptosis rates were markedly increased when treated with high dose
\end{abstract}

Correspondence to: Professor Yueyin Pan, Department of Oncology, The First Affiliated Hospital of Anhui Medical University, 218 Ji Xi Road, Hefei, Anhui 230022, P.R. China E-mail: panyueyin1965@126.com

Professor Ying Zhang, Department of Geriatrics, The Third Affiliated Hospital of Anhui Medical University, 390 Huai He Road, Hefei, Anhui 230601, P.R. China

E-mail: ashywan@sina.com

Key words: non-small-cell lung cancer, drug therapy, gefitinib pulsatile gefitinib in PC9 cell line, while a decrease was noted in p-EGFR and p-AKT. These data suggest that high-dose pulsatile gefitinib treatment may overcome acquired resistance in NSCLC, though its efficacy is dependent on the type of drug resistance mutation(s) present. Furthermore, high-dose pulsatile gefitinib may inhibit tumor growth and induce cell apoptosis by blocking the EGFR signaling pathway. Therefore, if the signaling pathways involved in drug resistance are not activated by the EGFR gene, high-dose pulsatile gefitinib may have little efficacy in the treatment of NSCLC.

\section{Introduction}

Non-small cell lung cancer (NSCLC) is the predominant form of lung cancer and accounts for $80-85 \%$ of all lung carcinomas (1). Recently there has been a change in the management strategies of NSCLC, possibly due to implications from a number of large-scale clinical trials indicating that platinum-based chemotherapy has reached a therapeutic plateau (2,3). Due to improving detection methods, NSCLC may be sub-classified by oncogenic mutations (4) and thus novel gene-targeting therapies may improve the prognosis of patients with NSCLC (5).

Inhibition of mutated epidermal growth factor receptor (EGFR) is considered to be key in the treatment of NSCLC (6). It has been established that EGFR-tyrosine kinase inhibitors (TKI) are superior to standard chemotherapy as a first-line treatment for patients with an EGFR mutation (7,8). However, patients who initially respond to EGFR-TKI still develop a progressive form of the disease and have a median progression free survival rate of $<1$ year (9).

Therefore, strategies to overcome NSCLC drug resistance warrant further study. Previous studies have indicated that re-initiation of EGFR-TKI may be an option for patients who previously exhibited EGFR-TKI resistance $(10,11)$, possibly due to repopulation of the tumor tissue by cancer cells responsive to EGFR-TKI. Small-sample clinical trials have also demonstrated that a number of patients exhibiting acquired resistance to EGFR-TKIs benefited from treatment with high-dose pulsatile TKIs $(12,13)$, potentially due to a dependence of resistant tumor cells on the EGFR signaling 
pathway. However, conventional TKI doses are not sufficient at inhibiting EGFR overexpression if a resistant cell population arises (14). Therefore, inhibition of EGFR signaling by high-dose pulsatile gefitinib may be a novel strategy for the treatment of NSCLC.

The EGFR pathway is frequently overexpressed in tumors, such as NSCLC, colorectal cancer and glioblastoma (15-17). The EGFR signal pathway serves a key role in the regulation of cell proliferation, induction of angiogenesis and the promotion of tumor cell invasion, metastasis and differentiation. The phosphoinositide 3-kinase (PI3K)/AKT and extracellular signal-regulated kinase (ERK)/mitogen activated protein kinase kinase (MEK) pathways are important downstream regulators of the EGFR signal pathway (18). It has been determined that tumor cell apoptosis is induced when the PI3K/AKT and MEK/ERK signal pathways are simultaneously blocked, suggesting that overactivation of AKT and ERK is associated with EGFR TKI resistance in NSCLC (19).

Gefitinib, a first generation drug, is a selective and reversible EGFR TKI. Gefitinib competitively binds to the tyrosine kinase domain of EGFR, which blocks the EGFR signal pathway and leads to the inhibition of cell proliferation and induction of apoptosis (20). The clinical benefit of gefitinib has been established in past studies of advanced NSCLC $(21,22)$ and a number of clinical trials have investigated whether continued use of TKIs may serve a role in the management of drug resistant NSCLC (23). The results of these trials suggested that higher drug doses may be effective and well tolerated in patients with advanced NSCLC.

Therefore, the present study aimed to determine the efficacy of high-dose pulsatile gefitinib in the treatment of NSCLC that exhibits acquired resistance to EGFR TKIs. To identify the effects and underlying mechanism of gefitinib, different doses of gefitinib were administered to gefitinib-sensitive and -resistant NSCLC cell lines in vitro. The cell viability was measured using an MTT assay. Cell apoptosis and cycling were also determined by flow cytometry and the expression of phospho (p)-EGFR, EGFR, p-AKT and AKT were measured by western blot analysis.

\section{Materials and methods}

Cell culture and drug preparation. The human NSCLC cell lines PC9, H1975 and H1650 were provided by the Guangdong Lung Cancer Institute at the Guangdong General Hospital (Guangdong Academy of Medical Sciences, Guangzhou, China). The EGFR-sensitive PC9 cell line had an activating EGFR E746-A750 deletion mutation (exon 19), while the EGFR-resistant H1975 and H1650 cells harbored EGFR L858R (exon 21)/T790M substitution (exon 20) and E746-A750 deletion mutations (exon 19), respectively. H1650 also had a homozygous deletion of the phosphatase and tensin homolog (PTEN) gene. Cell lines were maintained in Dulbecco's modified Eagle medium (DMEM; Hyclone; GE Healthcare, Logan, UT, USA) supplemented with $10 \%$ heat-inactivated fetal bovine serum (Hyclone; GE Healthcare, Logan, UT, USA), 100 U/ml penicillin, $100 \mu \mathrm{g} / \mathrm{ml}$ streptomycin and $2 \mathrm{mM} \mathrm{L}$-glutamine at $37^{\circ} \mathrm{C}$ in a $5 \% \mathrm{CO}_{2}$ incubator with saturated humidity for 1-2 days. Cells were harvested with trypsin-EDTA for use in experiments when they had reached exponential growth.
Gefitinib was obtained from AstraZeneca (Cambridge, UK) and was dissolved in dimethyl sulfoxide (DMSO) to a stock concentration of $10 \mathrm{mM}$. The solution was stored at $-20^{\circ} \mathrm{C}$ and diluted to the desired concentrations in fresh medium prior to experiments, as follows: $3.125,6.25,12.5,50,100,200$, $400 \mathrm{nmol} / \mathrm{l}$ in PC9 cell lines and 3.125, 6.25, 12.5, 50, 100, 200, $400 \mu \mathrm{mol} / 1$ in $\mathrm{H} 1975$ and $\mathrm{H} 1650$ cell lines. The final concentration of DMSO was $0.1 \%$.

Cell proliferation assay. A 3-(4,5-Dimethylthiazol-2-yl)2,5-diphenyltertrazolium bromide (MTT) assay was used to evaluate the viability of the PC9, H1975 and H1650 cells treated with gefitinib. Cells that were harvested and digested with trypsin at their logarithmic growth phase were re-suspended in DMEM supplemented with serum to adjust cell concentration. Cells were then seeded into 96 -well plates at a density of 3,000 cells/well, followed by overnight culture at $37^{\circ} \mathrm{C}$ and exposure to the different concentrations of gefitinib (as indicated) at $37^{\circ} \mathrm{C}$ for $72 \mathrm{~h}$. There were six replicate plates for each drug concentration group. A blank control group (culture medium alone) and control group (cells and medium without drug) were also established. Following incubation at $37^{\circ} \mathrm{C}$ for $72 \mathrm{~h}, 20 \mu \mathrm{l}$ MTT solution was added to each well. Cells were then incubated for $4 \mathrm{~h}$ at $37^{\circ} \mathrm{C}$ to allow formazan crystals to form. The crystals were subsequently dissolved by adding $150 \mu \mathrm{l}$ DMSO and absorbance of the resulting solutions was measured at $490 \mathrm{~nm}$ with a Multiskan JX microplate reader (Thermo Fisher Scientific, Inc. Waltham, MA, USA). Cell survival rate was calculated as [optical density (OD) value of experimental well - OD value of blank control well] / [OD value of no drug control well - OD value of blank control well $]$ x $100 \%$ cell inhibition rate [ $=1$ - (OD value of experimental well - OD value of blank control well) / (OD value of no drug control well - OD value of blank control well) x 100\%]. The half maximal inhibitory concentration $\left(\mathrm{IC}_{50}\right)$ of the drug was determined as the drug concentration that led to $50 \%$ cell growth inhibition relative to control cell growth. The drug resistance indices $=\mathrm{IC}_{50}$ (resistant cell) $/ \mathrm{IC}_{50}$ (sensitive cells). All experiments were performed in triplicate.

Cell apoptosis assay. Cells in their logarithmic growth phase were plated in DMEM supplemented with serum at a density of $1.0 \times 10^{5}$ cells/well into 6 -well plates and incubated at $37^{\circ} \mathrm{C}$ for $24 \mathrm{~h}$ prior to treatment with different concentrations of gefitinib (as indicated). According to the $\mathrm{IC}_{50}$ values determined by the MTT assay, cells were divided into an untreated control group, a standard gefitinib treatment group with a 1-fold $\mathrm{IC}_{50}$ value, a gefitinib pulsatile treatment group with a 2-fold $\mathrm{IC}_{50}$ value and a gefitinib high-dose pulsatile treatment group with a 4-fold $\mathrm{IC}_{50}$ value. Therefore, the gefitinib treatments were as follows: For PC9, control (0 nM), 30, 60 and $120 \mathrm{nM}$; for H1975, control, 20, 40 and $80 \mu \mathrm{M}$; and for $\mathrm{H} 1650$, control, 25, 50 and $100 \mu \mathrm{M}$. Following drug treatment, adherent and floating cells were collected, washed twice with phosphate-buffered saline (PBS) and re-suspended in $400 \mu \mathrm{l}$ $1 \mathrm{X}$ Annexin $\mathrm{V}$ buffer. A total of $5 \mu \mathrm{l}$ Annexin V-enhanced green fluorescent protein was then added and the cells were incubated at room temperature for $15 \mathrm{~min}$ in the dark, followed by incubation with $10 \mu \mathrm{l}$ propidium iodide (PI) at room temperature for $5 \mathrm{~min}$ in the dark. The apoptosis 
detection kit was purchased from BD Biosciences (Franklin Lakes, NJ, USA). Stained cells were then analyzed with a flow cytometer and data were analyzed by Cell Quest v.6.0 software (BD Biosciences).

Cell cycle analysis. Cells in their logarithmic growth phase were plated in DMEM supplemented with serum at a density of $1.0 \times 10^{5}$ cells/well into 6 -well plates and left to adhere to the well overnight at $37^{\circ} \mathrm{C}$. Following incubation for $24 \mathrm{~h}$, cells were treated with different concentrations of gefitinib for $72 \mathrm{~h}$ at $37^{\circ} \mathrm{C}$ and $5 \% \mathrm{CO}_{2}$. The gefitinib treatments were as follows: For PC9, control (0 nM), 30, 60 and $120 \mathrm{nM}$; for $\mathrm{H} 1975$, control, 20, 40 and $80 \mu \mathrm{M}$; and for H1650, control, 25, 50 and $100 \mu \mathrm{M}$. Cells were then collected, washed in PBS and fixed in $70 \%$ ethanol at $4^{\circ} \mathrm{C}$ overnight. Prior to analysis, cells were treated with $50 \mu \mathrm{g} / \mathrm{ml}$ PI and $200 \mu \mathrm{g} / \mathrm{ml}$ RNAse A (Sigma-Aldrich; Merck Millipore, Darmstadt, Germany) for $30 \mathrm{~min}$ at $4^{\circ} \mathrm{C}$ in the dark. Stained cells were analyzed by flow cytometry using a MoFlo cell sorter (Dako; Agilent Technologies, Inc., Santa Clara, CA, USA) and ModFit LT v.4.0 software (Verity Software House, Inc., Topsham, ME, USA).

Western blot analysis. Cells were seeded at a density of $1.0 \times 10^{6}$ cells/well into 6 -well plates for $24 \mathrm{~h}$. The experiment group was divided into control $(0 \mathrm{nM}), 30,60$ and $120 \mathrm{nM}$ in PC9; control, 20, 40 and $80 \mu \mathrm{M}$ in H1975; and control, 25, 50 and $100 \mu \mathrm{M}$ in $\mathrm{H} 1650$. Following incubation with or without gefitinib for $48 \mathrm{~h}$ at $37^{\circ} \mathrm{C}$, cells were harvested and lysed in ice-cold lysis buffer. Cells were incubated on ice for $20 \mathrm{~min}$ following centrifugation for $30 \mathrm{~min}$ at $12,000 \mathrm{x} \mathrm{g}$ and $4^{\circ} \mathrm{C}$, and collection of the supernatant. The protein concentration of each sample was determined using a Bicinchoninic Acid Protein assay kit (Beyotime Institute of Biotechnology, Haimen, China). Samples containing equal quantities $(30 \mu \mathrm{g})$ of protein were analyzed by $10 \%$ SDS-PAGE and transferred to polyvinylidene difluoride membranes (EMD Millipore, Billerica, MA, USA). Membranes were blocked with PBS containing 5\% skim milk and $0.1 \%$ Tween-20 for 1-2 h. Subsequently, protein was incubated with primary antibodies for EGFR (2256), AKT (9272), p-EGFR (2244), p-AKT (9271) and $\beta$-actin (as a loading control; 4970; all 1:1,000) overnight at $4^{\circ} \mathrm{C}$, followed by incubation with a horseradish peroxidase-conjugated secondary antibody $(1: 5,000)$ at room temperature for $1 \mathrm{~h}$. Two types of the secondary antibody were used, including anti-mouse immunoglobulin (Ig) G (7076) and anti-rabbit IgG (7074). All antibodies were purchased from Cell Signaling Technology, Inc. (Danvers, MA, USA). Image J v. 1.48 software (National Institutes of Health, Bethesda, MD, USA) was used for protein band detection using enhanced chemiluminescence reagents (EMD Millipore) and for analysis of the gray value of protein bands.

Statistical analysis. At least three independent experiments were performed for each procedure. Quantified data were analyzed by the Student's one-way analysis of variance. SPSS v. 16.0 software (SPSS, Inc., Chicago, IL, USA) was used to analyze all results. Data are presented as the mean \pm standard deviation and $\mathrm{P}<0.05$ was considered to indicate a statistically significant difference.

\section{Results}

Differential antiproliferative effects of gefitinib in NSCLC cell lines. The antiproliferative effects of gefitinib on the PC9,H1975 and H1650 cell lines were determined by an MTT assay. Cells were exposed to various concentrations of gefitinib for $72 \mathrm{~h}$ in order to detect the differential sensitivity of the EGFR-mutant cell lines to gefitinib. The resulting growth-inhibitory curves are depicted in Fig. 1. From the relevant literature, $\mathrm{IC}_{50}<1 \mu \mathrm{M}$ confers gefitinib sensitivity to EGFR-TKI, while $\mathrm{IC}_{50}>1 \mu \mathrm{M}$ confers gefitinib resistance to EGFR-TKI (24). Thus, the EGFR-sensitive PC9 cells exhibited sensitivity to gefitinib, with an $\mathrm{IC}_{50}$ value of $29.61 \pm 0.72 \mathrm{nM}$ (Fig. 1A), while the EGFR-resistant H1975 and H1650 cells exhibited resistance to gefitinib, with $\mathrm{IC}_{50}$ values of $19.25 \pm 1.31 \mu \mathrm{M}$ (Fig. 1B) and $21.729 \pm 1.16 \mu \mathrm{M}$ (Fig. 1C), respectively. The drug resistance indices of H1975 and H1650 cells were 1,000-fold higher than that of PC9, and statistical analysis indicated that the sensitivity of PC9 cells relative to H1975 and H1650 cells was significant $(\mathrm{P}<0.05)$.

Differential effect of gefitinib on NSCLC cell apoptosis. An apoptosis assay using Annexin V/PI staining was also performed following treatment of the PC9, H1975 and H1650 cell lines with gefitinib (Fig. 2A). According to $\mathrm{IC}_{50}$ values determined by the MTT assay, cells were divided into an untreated control group, a standard gefitinib treatment group with a 1 -fold $\mathrm{IC}_{50}$ value, a gefitinib pulsatile treatment group with a 2 -fold $\mathrm{IC}_{50}$ value and a gefitinib high-dose pulsatile treatment group with a 4-fold $\mathrm{IC}_{50}$ value. From Fig. 2, the results demonstrated that apoptotic rates were $0.04 \pm 1.61,12.72 \pm 1.73,28.94 \pm 1.34$ and $38.04 \pm 1.57 \%$ in PC9 cells, $3.28 \pm 1.53,9.61 \pm 1.78,14.04 \pm 1.45$ and $24.09 \pm 1.38 \%$ in H1975, while $0.55 \pm 0.98,1.06 \pm 1.01$, $1.076 \pm 1.07$ and $1.595 \pm 1.04 \%$ in H1650. For PC9 and H1975 cells, it was observed that the pulsatile treatment groups had significantly higher apoptotic rates than the control groups of the PC9 and H1975 cell lines, respectively $(\mathrm{P}<0.01)$, with more marked increases in the apoptotic rates of the PC9 treatment groups than in those of the H1975 treatment groups, relative to their respective control groups (Fig. 2B). In the H1650 cell line, there was no significant difference in the apoptotic rates of treatment groups relative to control cells ( $\mathrm{P}>0.05$; Fig. 2B).

Differential effect of gefitinib on cell cycle progression. To evaluate cell cycle phase distribution following gefitinib treatment, $\mathrm{PC} 9, \mathrm{H} 1975$ and $\mathrm{H} 1650$ cells treated with different concentrations of gefitinib were analyzed by flow cytometry. As depicted in Fig. 3, in PC9 and H1975 cells, the population of cells arrested in the G0/G1 phase increased significantly compared with the control groups following treatment with $120 \mathrm{nM}$ and $80 \mu \mathrm{M}$ gefitinib, respectively $(\mathrm{P}<0.01$; Fig. 3A and B). By contrast, there were no significant differences in cell cycle distribution among any treatment groups of the $\mathrm{H} 1650$ cell line ( $\mathrm{P}>0.05$; Fig. $3 \mathrm{C}$ ), which is in line with results from flow cytometry.

Differential effects of gefitinib on EGFR-mediated signaling. The PI3K/AKT and MEK/ERK signal pathways are important downstream regulators of the EGFR signal pathway. In addition, tyrosine phosphorylation of EGFR and AKT has 

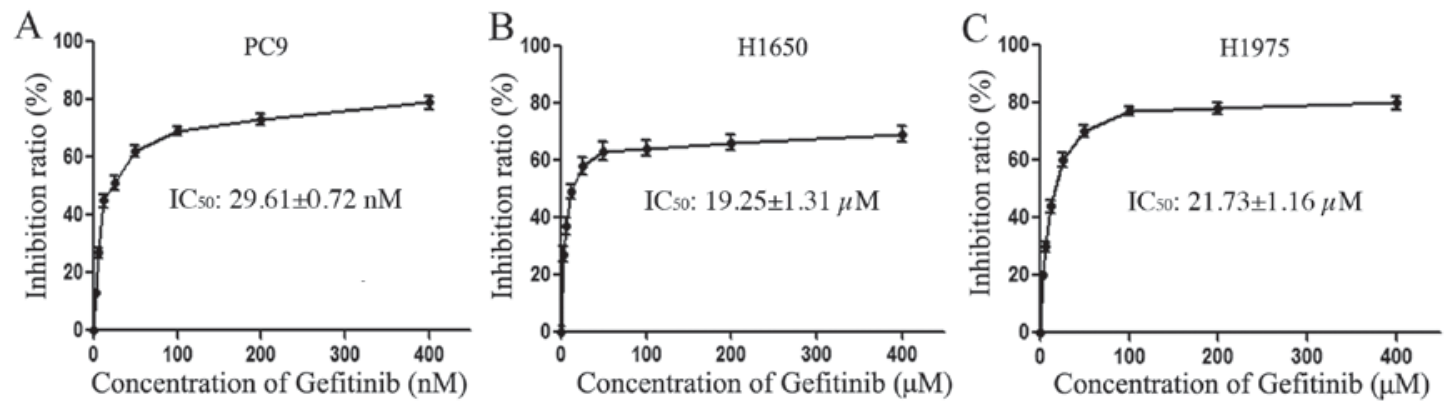

Figure 1. Viability of NSCLC cells following gefitinib treatment. The NSCLC cell lines, (A) PC9 and (B) H1975 and (C) H1650, were exposed to increasing concentrations of gefitinib (3.125-400 $\mathrm{nM}$ and 3.125-400 $\mu \mathrm{M}$, respectively) and cell viability was measured by an MTT assay. The half maximal inhibitory concentration values are presented as the mean \pm standard deviation of three independent experiments. NSCLC, non-small cell lung cancer.
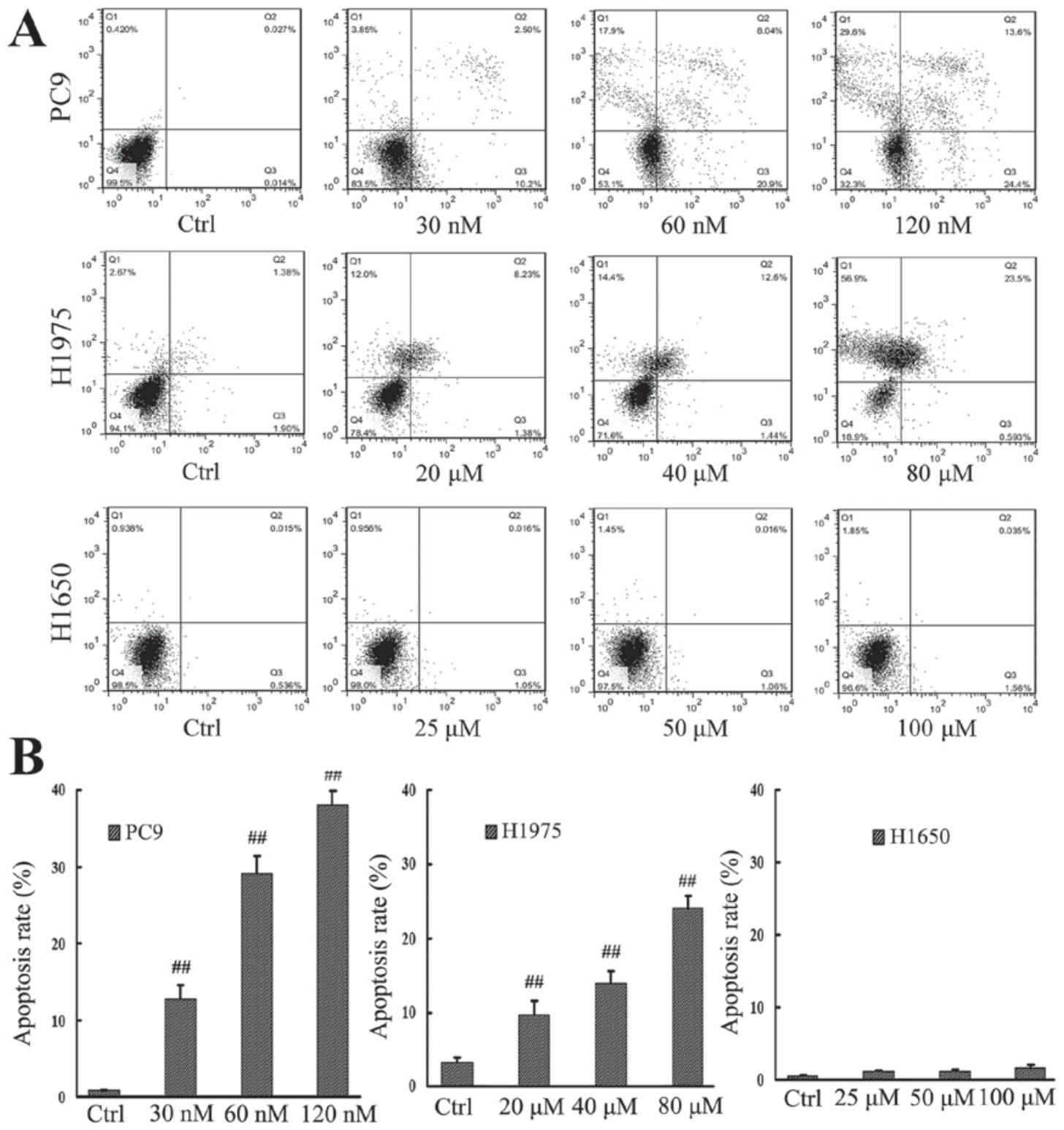

Figure 2. Apoptotic rate of NSCLC cells following gefitinib treatment. (A) NSCLC cell lines, PC9, H1975 and H1650, were exposed to increasing concentrations of gefitinib and cell apoptosis was measured by an Annexin V/propidium iodide double staining assay. (B) Apoptotic rates of individual cells lines. ${ }^{\# \#} \mathrm{P}<0.01$ vs. untreated $\mathrm{Ctrl}$ of the respective cell lines. NSCLC, non-small cell lung cancer; Ctrl, control.

been implicated in tumor cell proliferation (25). In order to investigate the underlying anti-proliferative mechanisms of high-dose pulsatile gefitinib treatment, levels of p-EGFR and pAKT in the gefitinib-treated cell lines were measured by 

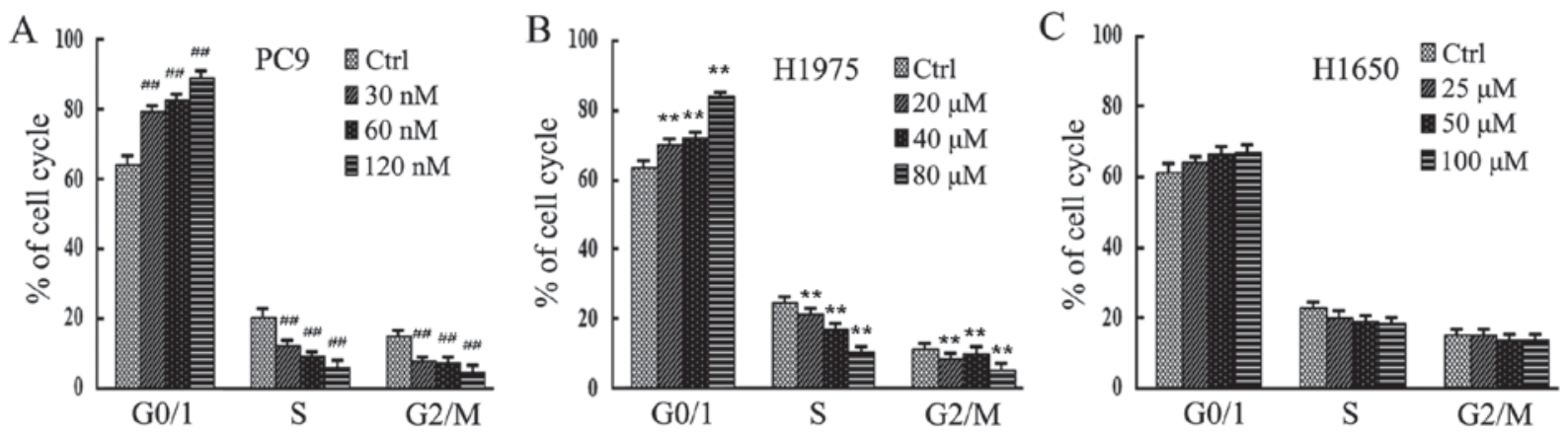

Figure 3. Cell cycle phase distribution of NSCLC cells following gefitinib treatment. The NSCLC cell lines, (A) PC9, (B) H1975 and (C) H1650, were exposed to increasing concentrations of gefitinib and cell cycle phase distribution was measured by flow cytometry. ${ }^{\# \#} \mathrm{P}<0.01$ and ${ }^{* * *} \mathrm{P}<0.01 \mathrm{vs}$. Ctrl. Ctrl, control.

$\mathbf{A}$

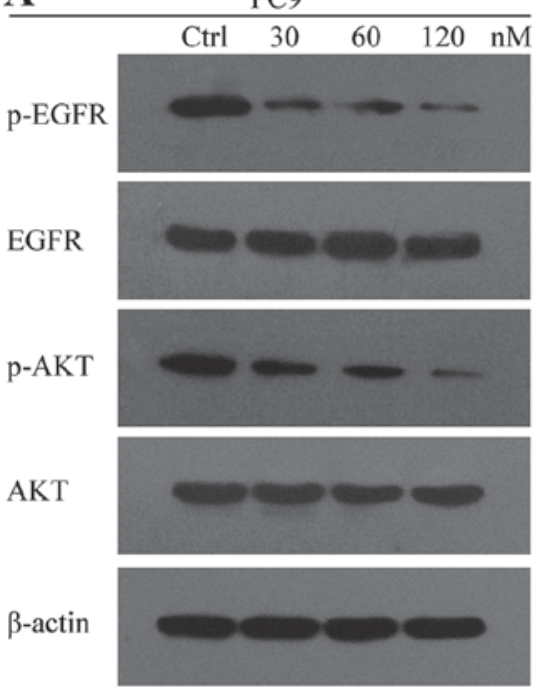

B

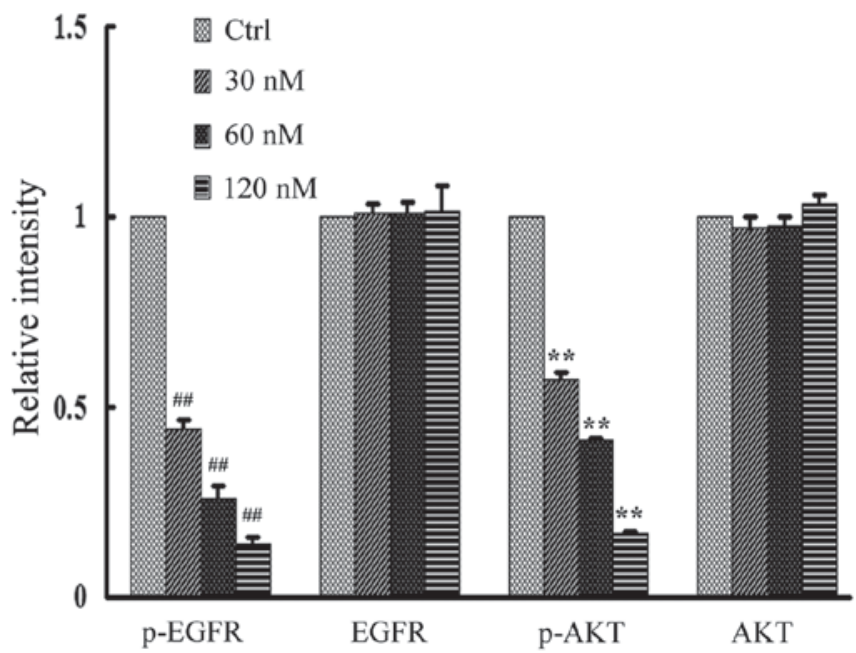

Figure 4. EGFR signaling assay in PC9 cells following gefitinib treatment. (A) Activation of EGFR and its downstream regulators was determined in PC9 cells by western blot analysis. (B) Quantification of relative protein intensities. ${ }^{\#} \mathrm{P}<0.01$ and ${ }^{* *} \mathrm{P}<0.01$ vs. Ctrl. EGFR, epidermal growth factor receptor; AKT, protein kinase B; p-, phosphorylated; Ctrl, control.

western blot analysis. It was observed that gefitinib inhibited the downstream signaling of EGFR in PC9 cells in a dose dependent manner, with levels of $\mathrm{p}-\mathrm{EGFR}$ and $\mathrm{p}-\mathrm{AKT}$ protein expression significantly decreased at all concentrations of gefitinib, relative to control cells $(\mathrm{P}<0.01$; Fig. 4). In H1975 cells, this effect was less evident, though significant decreases in the levels of p-EGFR and p-AKT at all concentrations of gefitinib, relative to control cells, were still observed $(\mathrm{P}<0.05$; Fig. 5). By contrast, there was no significant change in the level of p-AKT in H1650 cells (P>0.05), while p-EGFR significantly decreased at all concentrations of gefitinib, relative to control cells $(\mathrm{P}<0.05$; Fig. 6). There were no significant changes in the levels of total EGFR and AKT expression for all gefitinib-treated cell lines (Figs. 4-6).

\section{Discussion}

EGFR-TKIs are considered to be a key treatment strategy for patients with advanced-stage NSCLC. However, the development of acquired resistance limits improvements in overall patient prognosis. Remon et al (26) reported that the underlying mechanisms of TKI resistance may be grouped into four main categories: i) Secondary mutation in EGFR; ii) parallel activation of downstream signaling pathways; iii) phenotypic transformation of cells; iv) genetic alterations in addition to the EGFR mutation. Therefore, studies into targeted therapies specific for the different types of acquired resistance are warranted.

Previous studies have demonstrated that the EGFR-TKI erlotinib is an effective therapeutic option to treat patients with advanced NSCLC following gefitinib failure $(27,28)$. This may be due to the 'TKI-free interval' and differences in drug potencies, though it seems that the tumor cells retain partial dependence on EGFR signaling in their TKI-resistant state. In addition, increasing the dose of gefitinib following its treatment failure may be effective, with no dose-limiting toxicity observed (29), suggesting that the standard dose of gefitinib is inadequate. The high affinity of clinically used TKIs is also considered to be beneficial for patients experiencing relapse with acquired drug resistance following TKI therapy $(30,31)$. Collectively, these data suggest that high-dose pulsatile gefitinib may overcome the acquired resistance of NSCLC. In the present study, different TKI dose regimes and the underlying mechanisms of TKI resistance were evaluated, 
A

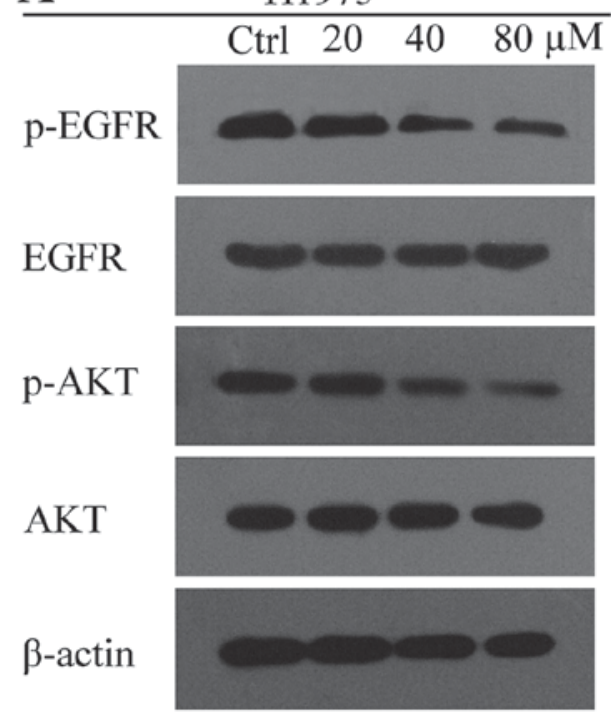

B

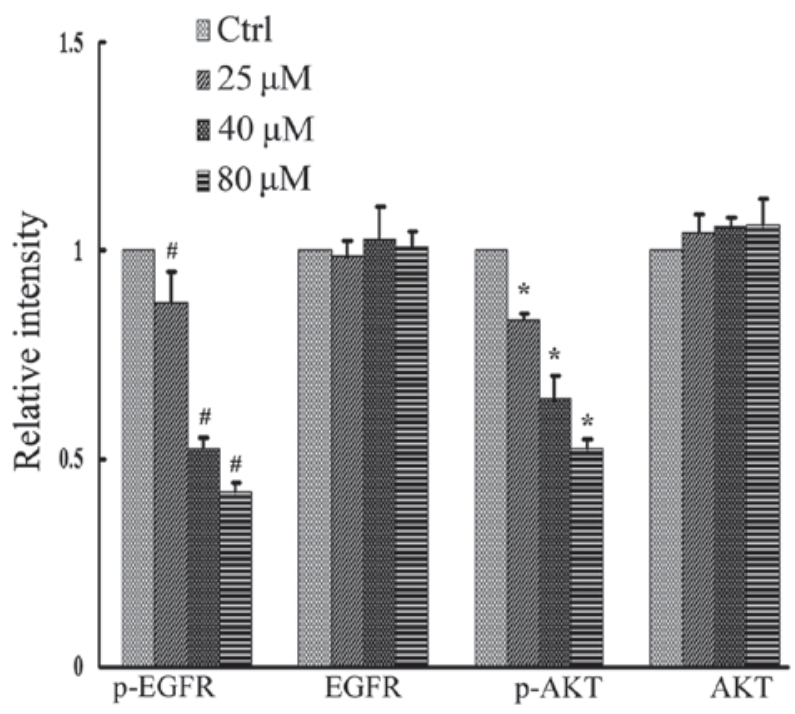

Figure 5. EGFR signaling assay in H1975 cells following gefitinib treatment. (A) Activation of EGFR and its downstream regulators was determined in H1975 cells by western blot analysis. (B) Quantification of relative protein intensities. ${ }^{\#} \mathrm{P}<0.05$ and ${ }^{*} \mathrm{P}<0.05$ vs. Ctrl. EGFR, epidermal growth factor receptor; AKT, protein kinase B; p-, phosphorylated; Ctrl, control.

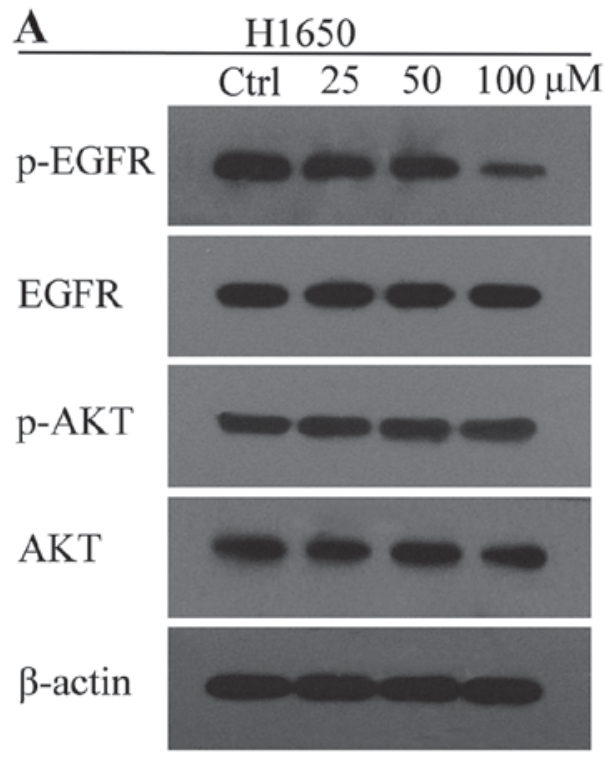

B

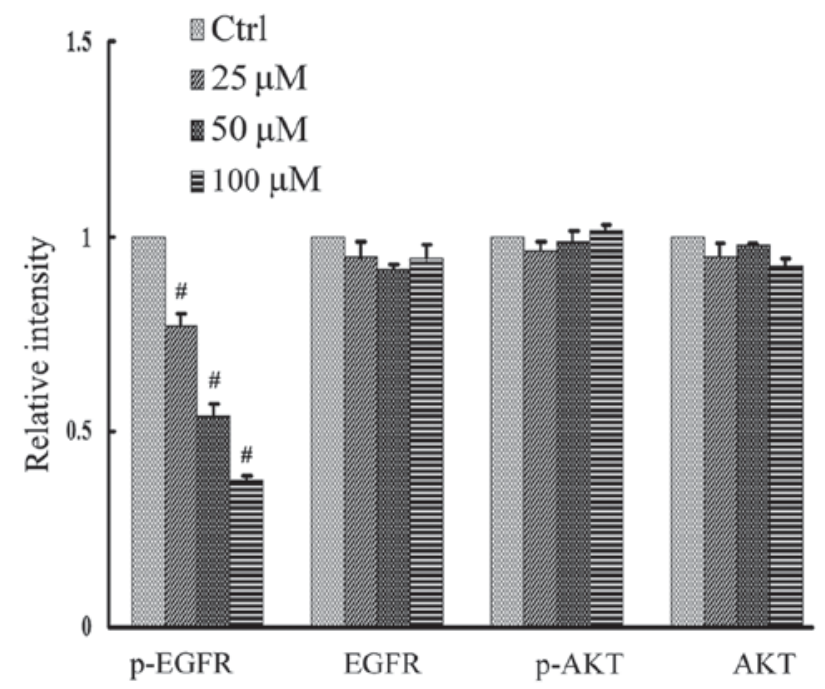

Figure 6. EGFR signaling assay in H1650 cells following gefitinib treatment. (A) Activation of EGFR and its downstream regulators was determined in H1650 cells by western blot analysis. (B) Quantification of relative protein intensities. ${ }^{\text {}} \mathrm{P}<0.05$ vs. Ctrl. EGFR, epidermal growth factor receptor; AKT, protein kinase (also known as protein kinase B); p-, phosphorylated; Ctrl, control.

using the gefitinib-sensitive PC9 and gefitinib-resistant H1975 and H1650 cell lines.

Growth of the cells was measured in vitro using a standard MTT assay and $\mathrm{IC}_{50}$ values were assessed following exposure of cells to different concentrations of gefitinib. The cell lines exhibited differential sensitivity to gefitinib, possibly due to the individual EGFR mutations in each cell line. Specifically, the $\mathrm{IC}_{50}$ values for H1975 and H1650 cells were higher than that for PC9 cells, which was consistent with their individual mutations. This was also consistent with results from the cell apoptosis assay, in which PC9 cells exhibited higher sensitivity to gefitinib than $\mathrm{H} 1975$ and $\mathrm{H} 1650$ cells. In PC9 cells, the apoptotic rate was significantly increased at all concentrations of gefitinib $(\mathrm{P}<0.01)$ and this was also observed in $\mathrm{H} 1975$ cells $(\mathrm{P}<0.01)$. This is in accordance with results from clinical trials, in which increasing the concentration of targeted inhibitors was effective in patients with renal cell carcinoma and gastrointestinal stromal tumor $(32,33)$. However, the present study detected no significant differences in the apoptotic rates of the H1650 treatment groups.

Gefitinib serves a key role in the regulation of cell apoptosis (34). In particular, gefitinib is able to arrest cells in the G0/G1 phase of the cell cycle (35). The present study evaluated the effects of gefitinib on the cell cycle of the NSCLC. It was observed that a significant population of PC9 and H1975 cells were arrested in the G0/G1 phase at higher fold $\mathrm{IC}_{50}$ 
concentrations of gefitinib $(120 \mathrm{nM}$ and $80 \mu \mathrm{M}$, respectively; $\mathrm{P}<0.01)$. By contrast, there were no significant differences in cell cycle progression among the H1650 treatment groups. These results were in accordance with those of the cell apoptosis assay.

Overactivation of EGFR signaling initiates a kinase signaling cascade that collectively promotes tumor development, as well as inducing intrinsic and/or acquired resistance to targeted anticancer therapies (36). Therefore, to determine the antiproliferative effects of high-dose pulsatile gefitinib, the present study assessed the effects of gefitinib on EGFR signaling. The results of the western blot analysis indicated that gefitinib inhibited the activation of EGFR and its downstream effectors in PC9 cells, and significantly decreased levels of p-EGFR and p-AKT $(\mathrm{P}<0.01)$. This was also observed to a lesser extent in $\mathrm{H} 1975$ cells $(\mathrm{P}<0.05)$. In $\mathrm{H} 1650$ cells, there was a significant decrease in $\mathrm{p}-\mathrm{EGFR}(\mathrm{P}<0.05)$, though no significant decrease in $\mathrm{p}-\mathrm{AKT}$. These results may due to the presence of different EGFR mutations in each cell line.

H1975 cells have a specific threonine to methionine substitution mutation at residue 790 (T790M) in exon 20 of the EGFR gene. Recent data have demonstrated that the greater size of methionine relative to threonine physically hinders the binding of EGFR TKIs, while also increasing the adenosine triphosphate (ATP)-binding affinity of EGFR, thereby reducing the effect of EGFR TKIs (37). Therefore, high-dose pulsatile gefitinib may outcompete ATP in binding to EGFR, thus blocking EGFR signaling. In H1650 cells, the EGFR gene carries an activating E746-A750 deletion mutation, while also containing a homozygous PTEN deletion. It is generally considered that the loss of PTEN results in misregulation of AKT-dependent signaling (38), and previous results have indicated that loss of PTEN contributes to EGFR-TKI resistance in EGFR mutation-positive lung cancer through activation of AKT (39). In addition, it has been demonstrated that only simultaneous inhibition of the PI3K/AKT and MEK/ERK pathways has pro-apoptotic and antiproliferative effects (40). Therefore, the resistance of H1650 to high-dose pulsatile gefitinib in the current study may have been caused by persistent activation of AKT signaling due to loss of PTEN.

In conclusion, results of the present study indicate that high-dose pulsatile gefitinib may be a novel therapeutic for the targeting of TKI resistance in NSCLC. However, efficacy of gefitinib may be related to the type of EGFR mutation in each patient, due to its observed inhibitory effects on EGFR signaling and tumor cell activity. Furthermore, high-dose pulsatile gefitinib is ineffective if downstream signaling of EGFR occurs independently of EGFR activation.

\section{Acknowledgements}

The authors would like to thank Professor Yue-yin Pan (Department of Oncology, The First Affiliated Hospital of Anhui Medical University, Hefei, China) and Professor Ying Zhang (The Third Affiliated Hospital of Anhui Medical University, Hefei, China) for their technical assistance. The present study was supported by the Anhui Provincial Natural Science Research Program of Higher Education Institutions Foundation of China (grant no. KJ2012A157) and the Central Laboratory of The Third Affiliated Hospital of Anhui Medical University.

\section{References}

1. Siegel RL, Miller KD and Jemal A: Cancer statistics, 2015. CA Cancer J Clin 65: 5-29, 2015.

2. Takahashi K, Saito H, Hasegawa Y, Ando M, Yamamoto M, Kojima E, Sugino Y, Kimura T, Nomura F, Ogasawara T, et al: First-line gefitinib therapy for elderly patients with non-small cell lung cancer harboring EGFR mutation: Central Japan Lung Study Group 0901. Cancer Chemother Pharmacol 74: 721-727, 2014.

3. Zhou C, Wu YL, Chen G, Feng J, Liu XQ, Wang C, Zhang S, Wang J, Zhou S, Ren S, et al: Final overall survival results from a randomised, phase III study of erlotinib versus chemotherapy as first-line treatment of EGFR mutation-positive advanced non-small-cell lung cancer (OPTIMAL, CTONG-0802). Ann Oncol 26: 1877-1883, 2015.

4. Antonicelli A, Cafarotti S, Indini A, Galli A, Russo A, Cesario A, Lococo FM, Russo P, Mainini AF, Bonifati LG, et al: EGFR-targeted therapy for non-small cell lung cancer: Focus on EGFR oncogenic mutation. Int J Med Sci 10: 320-330, 2013.

5. Daniels MG, Bowman RV, Yang IA, Govindan R and Fong KM: An emerging place for lung cancer genomics in 2013. J Thorac Dis 5 (Suppl 5): S491-S497, 2013.

6. Steuer CE and Ramalingam SS: Targeting EGFR in lung cancer: Lessons learned and future perspectives. Mol Aspects Med 45: 67-73, 2015.

7. Han JY, Park K, Kim SW, Lee DH, Kim HY, Kim HT, Ahn MJ, Yun T, Ahn JS, Suh C, et al: First-SIGNAL: First line single-agent iressa versus gemcitabine and cisplatin trial in never-smoker swith adenocarcinoma of the lung. J Clin Oncol 30: 1122-1128, 2012.

8. Jänne PA, Ou SH, Kim DW, Oxnard GR, Martins R, Kris MG, Dunphy F, Nishio M, O'Connell J, Paweletz C, et al: Dacomitinib as first-line treatment in patients with clinically or molecularly selected advanced non-small-cell lung cancer: A multicentre, open-label, phase 2 trial. Lancet Oncol 15: 1433-1441, 2014.

9. Camidge DR, Pan W and Sequist LV: Acquired resistance to TKIs in solid turnouts: Learning from lung cancer. Nat Rev Clin Oncol 11: 473-481, 2014.

10. Oh IJ, Ban HJ, Kim KS and Kim YC: Retreatment of gefitinib in patients with non-small-cell lung cancer who previously controlled to gefitinib: A single-arm, open-label, phase II study. Lung Cancer 77: 121-137, 2012.

11. Tang C, Gao H, Li X, Liu Y, Li J, Qin H, Wang W, Qu L, An J, Yang S and Liu X: Different treatment orders achieved similar clinical results: A retrospective study for retreatment of epidermal growth factor receptor tyrosine kinase inhibitors in 120 patients with non-small-cell lung cancer. J Cancer Res Clin Oncol 140: 427-433, 2014.

12. Kuiper JL and Smit EF: High-dose, pulsatile erlotinib in two NSCLC patients with leptomeningeal metastases-one with a remarkable thoracic response as well. Lung Cancer 80: 102-105, 2013.

13. Grommes C, Oxnard GR, Kris MG, Miller VA, Pao W, Holodny AI, Clarke JL and Lassman AB: 'Pulsatile' high-dose weekly erlotinib for CNS metastases from EGFR mutant non-small cell lung cancer. Neuro Oncol 13: 1364-1369, 2011

14. Forde PM and Ettinger DS: Managing acquired resistance in EGFR-mutated non-small cell lung cancer. Clin Adv Hematol Oncol 13: 528-532, 2015.

15. Refaat A, Aminullah, Zhou Y, Kawanishi M, Tomaru R, Abdelhamed S, Shin MS, Koizumi K, Yokoyama S, Saiki I and Sakurai H: Role of tyrosine kinase-independent phosphorylation of EGFR with activating mutation in cisplatin-treated lungcancer cells. Biochem Biophys Res Commun 458: 856-861, 2015.

16. Sobani ZA, Sawant A, Jafri M, Correa AK and Sahin IH: Oncogenic fingerprint of epidermal growth factor receptor pathway and emerging epidermal growth factor receptor blockade resistance in colorectal cancer. World J Clin Oncol 7: 340-351, 2016.

17. Li X, Wu C, Chen N, Gu H, Yen A, Cao L, Wang E and Wang L: $\mathrm{PI} 3 \mathrm{~K} / \mathrm{Akt} / \mathrm{mTOR}$ signaling pathway and targeted therapy for glioblastoma. Oncotarget 7: 33440-33450, 2016.

18. Sharifnia T, Rusu V, Piccioni F, Bagul M, Imielinski M, Cherniack AD, Pedamallu CS, Wong B, Wilson FH, Garraway LA, et al: Genetic modifiers of EGFR dependence in non-small cell lung cancer. Proc Natl Acad Sci USA 111: 18661-18666, 2014. 
19. Janmaat ML, Kruyt FA, Rodriguez JA and Giaccone G: Response to epidermal growth factor receptor inhibitors in non-small cell lung cancer cells: Limited antiproliferative effects and absence of apoptosis associated with persistent activity of extracellular signal-regulated kinase or Akt kinase pathways. Clin Cancer Res 9: 2316-2326, 2003.

20. Grünwald V and Hidalgo M: Developing inhibitors of the epidermal growth factor receptor for cancer treatment. J Natl Cancer Inst 95: 851-867, 2003.

21. Choi MK, Hong JY, Chang WJ, Kim MJ, Kim SM, Jung HA, Do IG, Choi YL, Sun JM, Ahn JS, et al: A phase II trial of gefitinib monotherapy in pretreated patients with advanced non-small cell lung cancer not harboring activating EGFR mutations: Implications of sensitive EGFR mutation test. Cancer Chemother Pharmacol 75: 1229-1236, 2015.

22. Kiyota H, Okamoto I, Takeda M, Daga H, Naito T, Miyazaki M, Okada H, Hayashi H, Tanaka K, Terashima M, et al: Phase I and pharmacokinetic study of gefitinib and S-1 combination therapy for advanced adenocarcinoma of the lung. Cancer Chemother Pharmacol 71: 859-865, 2013.

23. Tamura T, Kagohashi K and Satoh H: Successful afatinib therapy after resistance to EGFR-TKI in a patient with advanced adenosquamous cell lung cancer. Oncol Res Treat 38: 316-317, 2015.

24. Xu R, Shen H, Guo R, Sun J, Gao W and Shu Y: Combine therapy of gefitinib and fulvestrant enhances antitumor effects on NSCLC cell lines with acquired resistance to gefitinib. Biomed Pharmacother 66: 384-389, 2012.

25. Janmaat ML, Kruyt FA, Rodriguez JA and Giaccone G: Response to epidermal growth factor receptor inhibitors in non-small cell lung cancer cells: Limited antiproliferative effects and absence of apoptosis associated with persistent activity of extracellular signal-regulated kinase or Akt kinase pathways. Clin Cancer Res 9: 2316-2326, 2003.

26. Remon J, Morán T, Majem M, Reguart N, Dalmau E, Márquez-Medina D and Lianes P: Acquired resistance to epidermal growth factor receptor tyrosine kinase inhibitors in EGFR-mutant non-small cell lung cancer: A new era begins. Cancer Treat Rev 40: 93-101, 2014.

27. Vasile E, Tibaldi C, Chella A and Falcone A: Erlotinib after failure of gefitinib in patients with advanced non-small cell lung cancer previously responding to gefitinib. J Thorac Oncol 3: 912-914, 2008

28. Hata A, Katakami N, Yoshioka H, Fujita S, Kunimasa K, Nanjo S, Otsuka K, Kaji R, Tomii K, Iwasaku M, et al: Erlotinib after gefitinib failure in relapsed non-small cell lung cancer: Clinical benefit with optimal patient selection. Lung Cancer 74: 268-73, 2011.
29. Hirano S, Sano K, Morii S, Morita A, Takeda Y, Uruga K, Sugiyama H, Kobayashi N and Kudo K: A case of lung adenocarcinoma successfully treated with dose-reescalated gefitinib after resistance was acquired. Gan To Kagaku Ryoho 36: 1333-1336, 2009 (In Japanese).

30. Liao BC, Lin CC and Yang JC. Second and third-generation epidermal growth factor receptor tyrosine kinase inhibitors in advanced nonsmall cell lung cancer. Curr Opin Oncol 27: 94-101, 2015.

31. Jiang $T$ and Zhou C: Clinical activity of the mutant-selective EGFR inhibitor AZD9291 in patients with EGFR inhibitor-resistant non-small cell lung cancer. Transl Lung Cancer Res 3: 370-372, 2014

32. Park I, Ryu MH, Sym SJ, Lee SS, Jang G, Kim TW, Chang HM, Lee JL, Lee H and Kang YK: Dose escalation of imatinib after failure of standard dose in Korean patients with metastatic or unresectable gastrointestinal stromal tumor. Jpn J Clin Oncol 39: 105-110, 2009.

33. Amato R, Zhai J, Willis J, Saxena S and DeFoe M: A phase II trial of intrapatient dose-escalated sorafenib in patients with metastatic renal cell carcinoma. Clin Genitourin Cancer 10: 153-158, 2012.

34. Rahman AF, Korashy HM and Kassem MG: Gefitinib. Profiles Drug Subst Excip Relat Methodol 39: 239-264, 2014.

35. Baselga $J$ and Arteaga CL: Critical update and emerging trends in epidermal growth factor receptor targeting in cancer. J Clin Oncol 23: 2445-2459, 2005.

36. Shostak K and Chariot A: EGFR and NF- $\kappa B$ : Partners in cancer. Trends Mol Med 21: 385-393, 2015.

37. Nurwidya F, Takahashi F, Murakami A, Kobayashi I, Kato M, Shukuya T, Tajima K, Shimada N and Takahashi K: Acquired resistance of non-small cell lung cancer to epidermal growth factor receptor tyrosine kinase inhibitors. Respir Investig 52: 82-91, 2014

38. Georgescu MM: PTEN tumor suppressor network in PI3K-Akt pathway control. Genes Cancer 1: 1170-1177, 2010.

39. Yamamoto C, Basaki Y, Kawahara A, Nakashima K, Kage M, Izumi H, Kohno K, Uramoto H, Yasumoto K, Kuwano M and Ono M: Loss of PTEN expression by blocking nuclear translocation of EGR1 in gefitinib-resistant lung cance cells harboring epidermal growth factor receptor-activating mutations. Cancer Res 70: 8715-8725, 2010.

40. Janmaat ML, Kruyt FAE, Rodriguez JA and Giaccone G: Response to epidermal growth factor receptor inhibitors in nonsmall cell lung cancer cells: Limited antiproliferative effects and absence of apoptosis associated with persistent activity of extracellular signal-regulated kinase or Akt kinase pathways. Clin Cancer Res 9: 2316-2326, 2003. 